Health \& Medicine | Anne Sved Williams

\section{Meltdown Moments}

When the emotions of perinatal mums are out of control

\begin{tabular}{|c|c|c|}
\hline $\begin{array}{l}\text { Entry into motherhood can be } \\
\text { testing period in any woman's } \\
\text { ife. Sleepless nights and the } \\
\text { esponsibility for a tiny person } \\
\text { are all the more difficult for } \\
\text { vomen living with psychiatric } \\
\text { vonditions. Associate Professor } \\
\text { Anne Sved Williams, an } \\
\text { academic psychiatrist at the } \\
\text { Jniversity of Adelaide, is } \\
\text { esearching the treatment of } \\
\text { nothers affected by mental } \\
\text { Il-health and their infants. } \\
\text { She has a particular interest in } \\
\text { porderline personality disorder } \\
\text { BPD), a condition in which } \\
\text { emotions are difficult to control } \\
\text { and understand. Her focus is } \\
\text { on helping mothers with BPD } \\
\text { or significant emotional turmoil } \\
\text { form better relationships with } \\
\text { :heir infants through a new } \\
\text { group therapy approach and } \\
\text { an innovative picture book for } \\
\text { families living with emotional }\end{array}$ & 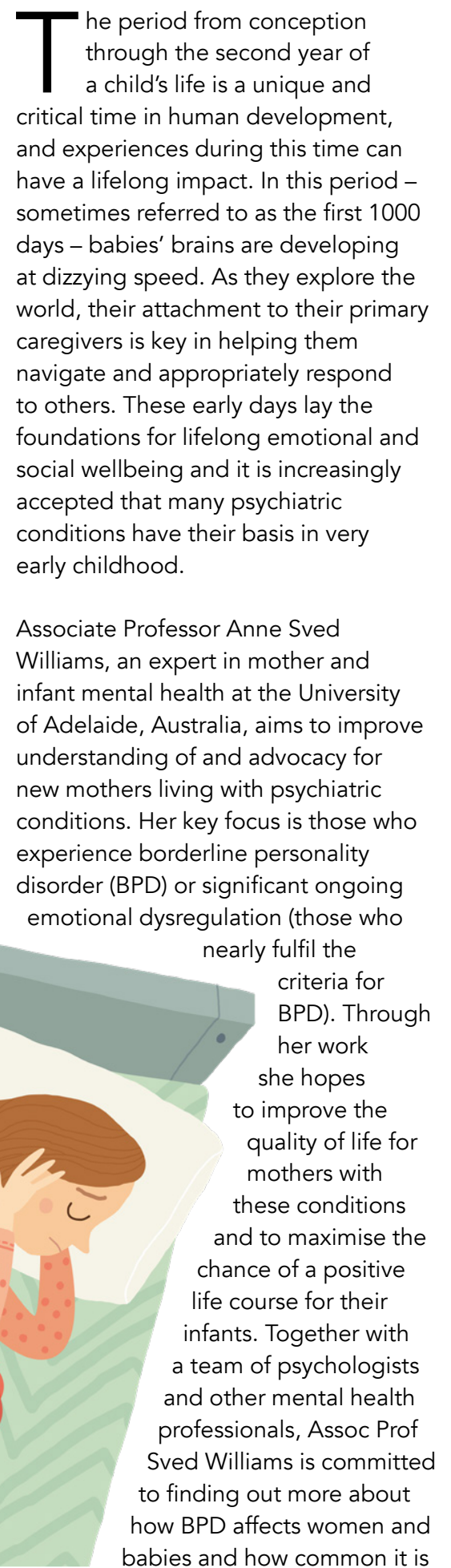 & $\begin{array}{l}\text { The } 2020 \text { coronavirus crisis and } \\
\text { its accompanying strict lockdown } \\
\text { measures mean her work is now more } \\
\text { relevant to many families with small } \\
\text { children around the world: Increased } \\
\text { pressure is being put on family life as } \\
\text { families grapple with being confined } \\
\text { to small spaces, dramatic economic } \\
\text { consequences, isolation, grief and fear } \\
\text { of infection. } \\
\text { BORDERLINE } \\
\text { PERSONALITY DISORDER } \\
\text { BPD is one of several personality } \\
\text { disorders - conditions that affect the } \\
\text { way that people think about and relate } \\
\text { to both themselves and to others. } \\
\text { People living with BPD often find it } \\
\text { difficult to control their emotions and } \\
\text { behaviours and, as a result, act very } \\
\text { impulsively. A common component } \\
\text { of BPD is emotional dysiegulation } \\
\text { (ED) that consistently disrupts how } \\
\text { people live their normal life. People } \\
\text { with BPD typically feel worried about } \\
\text { abandonment, have very intense } \\
\text { emotions, find it hard to maintain } \\
\text { friendships, and get angry very quickly. } \\
\text { Risk taking, paranoia and suicidal } \\
\text { thinking and behaviours are common. } \\
\text { Many with BPD have a history of } \\
\text { childhood trauma including sexual, } \\
\text { emotional or physical abuse, but more } \\
\text { recent theories suggest that parenting } \\
\text { styles may also have a central role in the } \\
\text { development of BPD. } \\
\text { HOW comMON Is } \\
\text { BPD IN NEW MUMS? } \\
\text { BPD is much more common than most } \\
\text { of us might assume with as many } \\
\text { as 6\% of people attending primary } \\
\text { healthcare having this sondition. The } \\
\text { Sved Williams grous is based in Helen }\end{array}$ \\
\hline
\end{tabular}

Mayo House, a mother-baby inpatient unit for mothers with psychological Chris Yelland from the group, showed Chis Yellond Adelide. A study led by the study were diagnosed with $B P D_{1}$ and almost half the admitted women showed features of BPD on a self-report measure. BPD was found to be much more prevalent than better-known conditions including post-partum psychosis and bipolar disorder.

Motherhood is a testing time for anyone but can trigger mental illness in those living with a mental health condition. Sleepless nights, body changes, birth recovery, impact on elationships and the constant demands fon infant can exacerbate existing with previously undigns Mas PPD or DD who are normally able to manage their condition find that they no longer can. They experience low mood, suicidal thoughts, angry outbursts and difficulty in caring for their babies. The infants are often unsettled and may have additional issues with feeding and sleeping. Consequently, the relationship between parent and child is compromised: a mother may experience difficulty relating to her baby and to her own emotions. The situation can rapidly deteriorate.

Assoc Prof Sved Williams and her team recently carried out a study exploring haw's cyis Con BD respond to their baby's crying. Common themes that women with BPD typically experienced intense emotional pain and cognitive chaos and often mentioned suicidal and infanticidal thoughts in response to the crying. These results highlight the need for urgent intervention.

AN OVERLOOKED CONDITION Assoc Prof Sved Williams - a form director of Helen Mayo House believes that BPD is often underdiagnosed and under-recognised particularly compared to postnata depression, leaving psychological therapies that could help patients ou of reach. Given the high prevalence of borderline personality disorder and emotional dystegnlation identified in

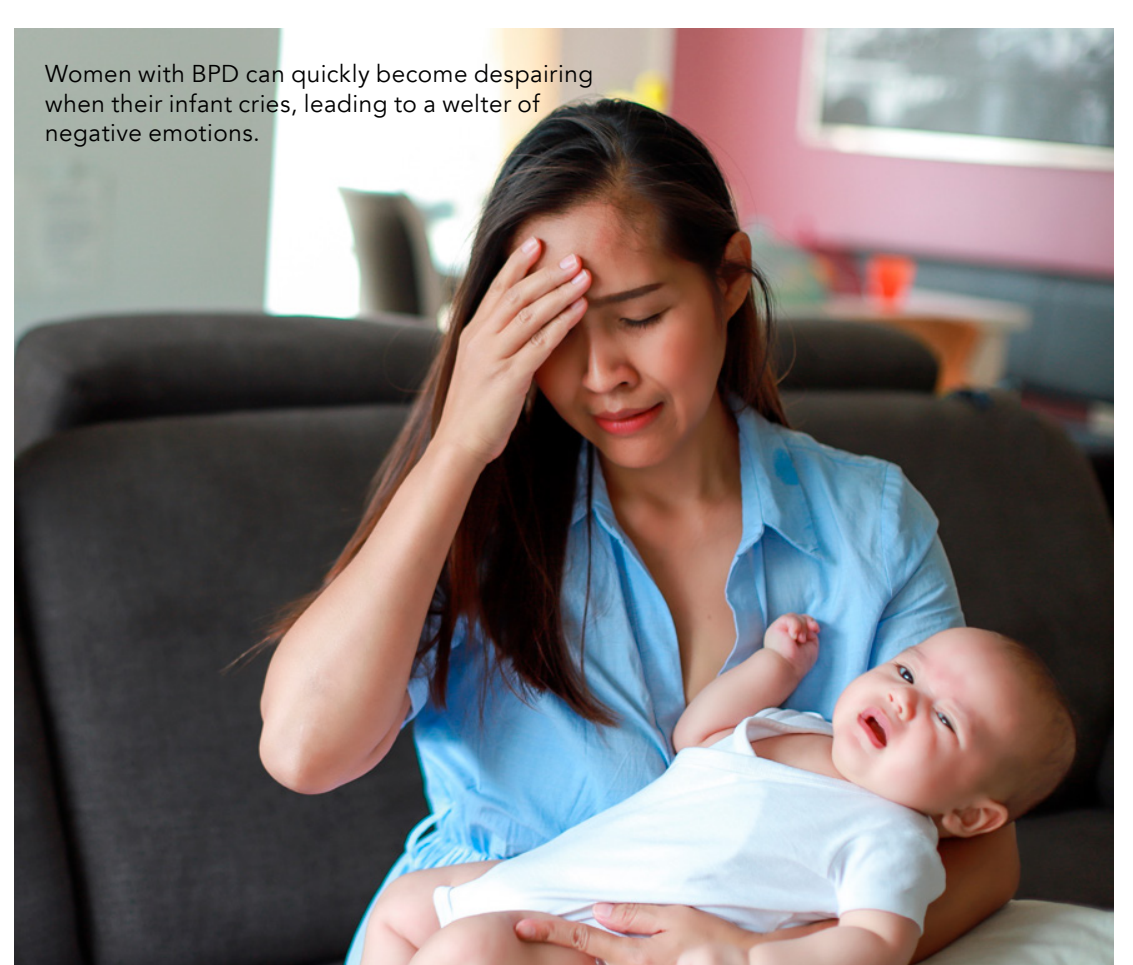

BPD was found to be more prevalent than better-known conditions including post-partum psychosis and bipolar disorder.

to do more to help these women and ensure the wellbeing of their infants.

INTERVENING TO

HELP MUM AND BABY

Given the surprisingly small number

the absence of those which involve therapy with both mother and baby, the team has embarked on a new approach to tailor psychotherapy interventions specifically for this roubled grop. A key an of their initial

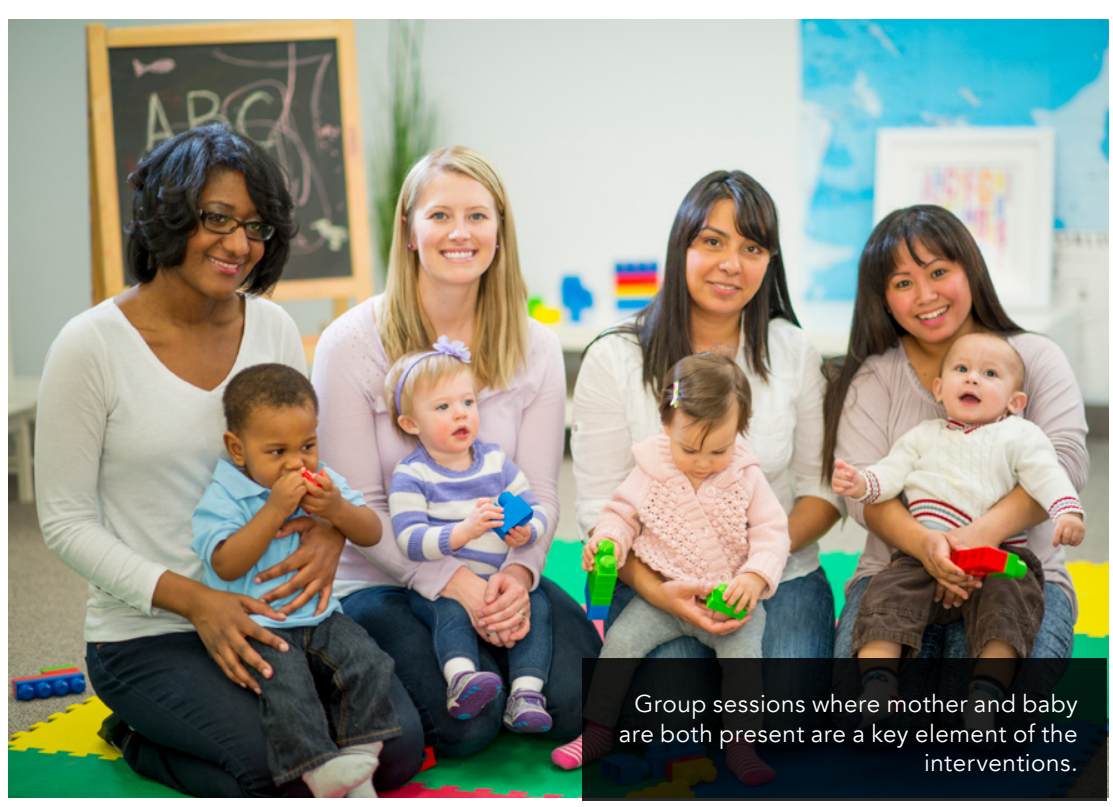




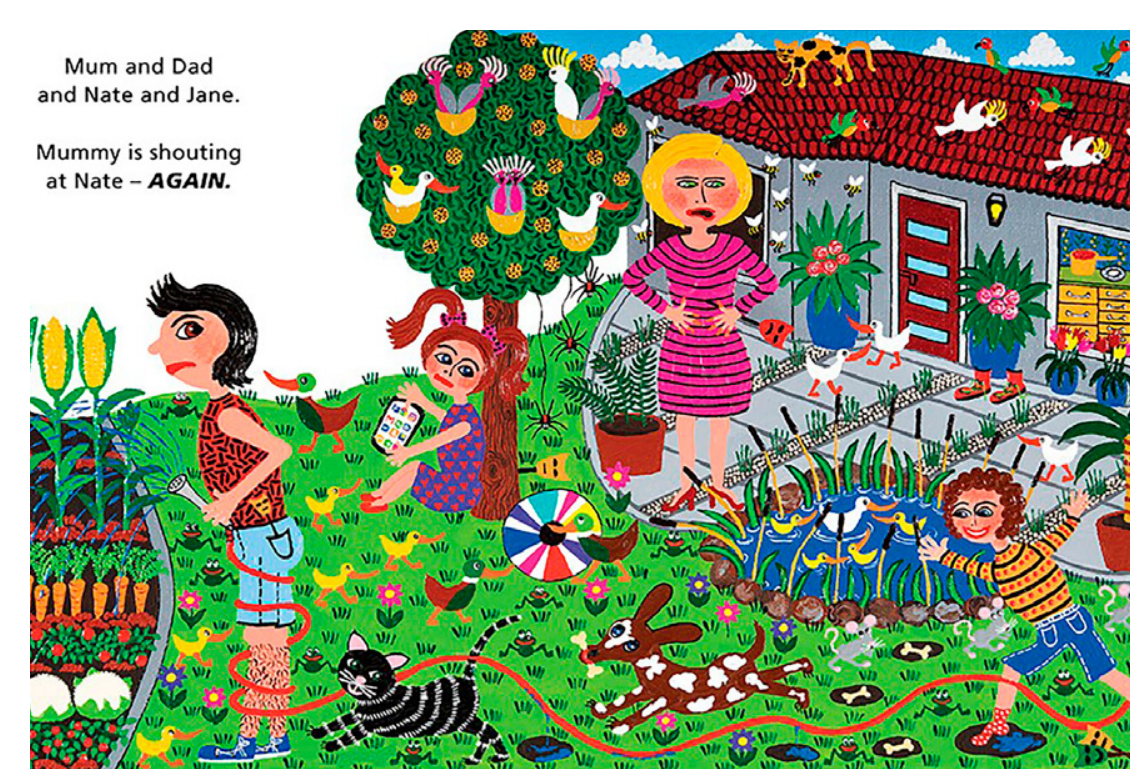

3 -

babies access the program as early as possible. Early intervention comes at becoming established in the motherbaby relationship and can potentially prevent damaging behaviours becoming entrenched.

The new intervention is based on dialectical behaviour therapy (DBT) a type of psychotherapy developed by Dr Marsha Linehan that aim to help people who experience overwhelming emotions accept their emotions, change harmful behaviours and improve close

Mother-infant DBT (MI-DBT) is adapted to focus on the relationship between mother and baby. Taking the components of DBT, it involves 24 group sessions over 24 weeks, comprising elements including distres management therapy and intense education on infant development and socialisation. A pilot study has shown very promising results, with improvements in mood, reduced anxiety, better emotional regulation and some improvement in parenting Scores on a parent-baby interaction index showed some improvement for a majority of the pairs. An analysis of a as yet unpublished confims mast as yet unpublished
results for mothers.

\section{MELTDOWN MOMENTS} Assoc Prof Sved Williams is committed emotional dysregulation and its more severe manifestation, BPD. She has recently published guidelines with Professor Gisele Apter, Chair of Child and Adolescent Psychiatry, Groupe Hospitalier du Havre in France, aimed at general practitioners to help them spot troubling signs in infants. Improving understanding
of BPD is also crucial within the family unit

itself and could help families manage the condition. To that end, Assoc Prof Sved Marie Jonsson-Harrison to create an innovative picture book, Meltdown Moments: Helping families to have conversations about mental health, their feelings and experiences. The book is available on Amazon (https://www amazon.co.uk/Meltdown-Momentsfamilies-conversations-experiences/ dp/0646809474) and all profits go to the Women's and Children's Hospital in Adelaide. Families can read the book with their small children to help then to understand BPD/ED and encourage conversations about what the family might do to change things. Following the
16-page picture story, Assoc Prof Sved

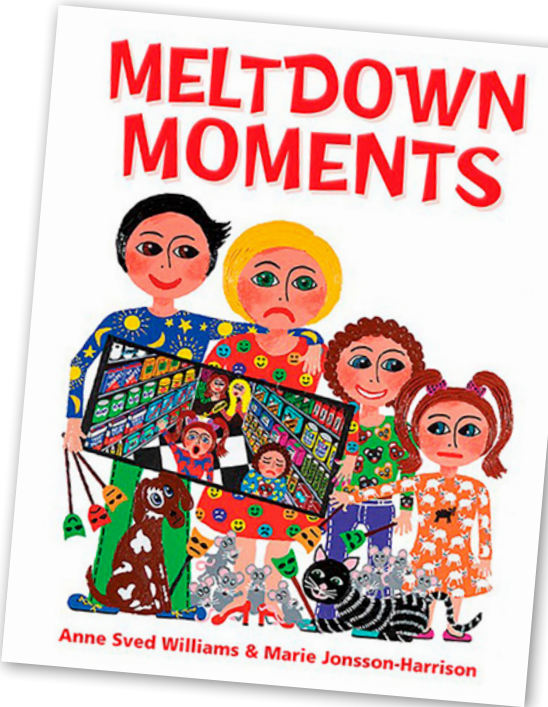

Williams has provided several pages of psycho-educational material about BPD, emotional dysregulation, parenting and getting help.

TIME IS OF THE ESSENCE Infants' needs are urgent and timely interventions are essential to ensure mothers. Early indications from the MI-DBT trial showed that there is excellent retention in the groups with Community-based referrals and word-of-mouth interest in the study and group interventions specifically fc mother-baby relationships. been exceptionally high leading to a much wider expansion of the program in South Australia, with promising results from these community-based groups as yet unpublished. This uptake is encouraging but also underlines the urgent need for program refinements, better resources in places other than Adelaide and help for these mothers and babies living in the community. Like all parents, mothers with BPD want to do the best by their children and commonly speak of their concern about passing BPD to their children. Assoc Prof Sved Wililiams' work makes the crucial early intervention possible, mental health and secure theirins lifelong emotional wellbeing.

\section{Behind the Research}

Assoc Prof Anne Sved Williams

E: Anne.SvedWilliams@sa.gov.au T: $+\frac{+61882698148}{\text { T: }}+\underline{+61870871047}$ W: http://www.wch.sa.gov.au/services/az/divisions/mentalhealth/helenmayo/index.html

References

Apter, G., and Sved Williams, A. (2018). Infants of motionally dysregulated or borderline personality disordered mothers: Issues and management in primary care. Australian journal of general practice,

Geerling, I., Roberts, R., and Sved Williams, A. (2019) Impact of infant crying on mothers with a diagnosis of Mental Health Journal, 40(3), 405-421.

Linehan, M., DBT Skills Training Manual, Second Edition, 2015

Sved Williams, A. (Author) and Jonsson-Harrison, M. (Illustrator) (2019). Meltdown Moments: Helping their feelings and experiences. Woun's and Children's Health Network. [Accessed 27 March 2020], https: $/ 1$ " wchfoundation. org aus and available on Amazon on https://www.amazon.com/Meltdown-Moments-familiesconversations-experiences/dp/0646809474

Sved Williams, A., Yelland, C., Hollamby, S., Wigley, M., nd Aylward, P. (2018). A New Therapeutic Group to Help Women with Borderline Personality Disorder and Their
Infants. Journal of Psychiatric Practice, 24(5), 331-340. Sved Williams, A., Apter, G. (2017). Helping mothers with the emotional dysregulation of borderline personal it Australian Family Physician 46(9), 669-672.

Yelland, C., Girke, T., Tottman, C., and Sved Williams, A.S. (2015). Clinical characteristics and mental health outcomes for wom chadmited to an Australlan Moth and emotional dysregulation? Australian Psychiatry $23(6), 683-7$

Perinatal and Infant Mental Health Services (PIMHS) Helen Mayo House [online]. Available at: http://www.wch. index.html [Accessed 27 March 2020].

Let Me Make You Smile [online]. Available at: $h$ ttp://
mariejonssonharrison.com.au/ [Accessed 27 March 2020].

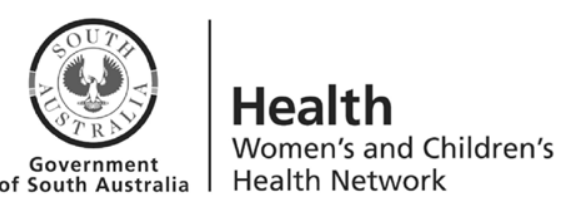

\section{Research Objectives}

Assoc Prof Anne Sved Williams has studied the effectiveness
of an innovative mother-infant focused dialectical behaviour of an innovative mother-infant focused dialectical behaviour therapy program in improvin
mother-infant relationships

\section{Detail}

Anne Sved Williams

Helen Mayo House, Glenside Hospital, South Australia

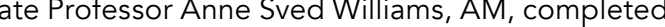
psychiatric training after ten years of general practice in Australia and he UK, and famly the rapy training at the ackerman Institute, New Yoars as medical unit head of South Australia's mother-baby unit and is a well-known teacher of perinata and infant mental health.

Funding

Hopscotch Foundation

- Chris Yelland

- Sharron Hollamby

- Marie Jonsson-Har

- Rebecca Hill

\section{Personal Response}

Ideally, how should your therapy be incorporated into rapy methods for BPD?

II Mothers really appreciate working with other mothers the mothers meet and their infants are provided with care. This also allows for the therapists to help the mothers with separations and reunions as the mums head to the group and back from it. They spend the last 20 minutes of group time with their infants present, practising with their infants so the focus is all on parenting.

sthere an element of your work you find most enjoyable?

I love knowing we are offering something very unique which course of their infants, and perhaps their partners too. 